\title{
Differential expression of immunologic proteins in gingiva after socket preservation in mini pigs
}

\author{
Seunggon JUNG ${ }^{1 *}$, Hee-Young YANG ${ }^{2 *}$, Tae-Hoon LEE²,3 \\ 1- Department of Oral and Maxillofacial Surgery, School of Dentistry, Chonnam National University, Gwangju, Republic of Korea. \\ 2- Department of Oral Biochemistry, Dental Science Research Institute, Medical Research Center for Biomineralization Disorders, School of Dentistry, Chonnam \\ National University, Gwangju, Republic of Korea. \\ 3- Department of Molecular Medicine, Graduate School, Chonnam National University, Gwangju, Republic of Korea. \\ *These authors contributed equally to this work.
}

Corresponding address: Tae-Hoon Lee - Department of Oral Biochemistry - School of Dentistry - Chonnam National University - 77 Yongbong-ro - Buk-gu - Gwangju 500-757 - Republic of Korea - Phone: +82-62-530-4842 - Fax: +82-62-530-4848 - e-mail: thlee83@chonnam.ac.kr

Submitted: August 14, 2014 - Modification: January 11, 2015 - Accepted: January 27, 2015

\section{ABSTRACT}

\begin{abstract}
$\mathrm{D}$ uring healing following tooth extraction, inflammation and the immune response within the extraction socket are related to bone resorption. Objective: We sought to identify how the alloplastic material used for socket preservation affects the immune responses and osteoclastic activity within extraction sockets. Material and Methods: Using a porcine model, we extracted teeth and grafted biphasic calcium phosphate into the extraction sockets. We then performed a peptide analysis with samples of gingival tissue from adjacent to the sockets and compared the extraction only (EO) and extraction with socket preservation (SP) groups. We also used real-time polymerase chain reaction (PCR) to evaluate the expression level of immunoglobulins, chemokines and other factors related to osteoclastogenesis. Differences between the groups were analyzed for statistical significance using paired $t$ tests. Results: Levels of IgM, IgG and IGL expression were higher in the EO group than in the SP group 1 week post-extraction, as were the levels of CCL3, CCL5, CXCL2, IFN- $\gamma$ and TNF- $\alpha$ expression $(p<0.05)$. In addition, receptor activator of nuclear factor kappa-B ligand (RANKL) was also significantly upregulated in the EO group $(p<0.05)$, as were IL-1 $\beta$, IL-6 and IL-8 $(p<0.05)$. Conclusions: These results suggest that the beneficial effect of socket preservation can be explained by suppression of immune responses and inflammation.
\end{abstract}

Keywords: Tooth socket. Tooth extraction. Alveolar bone loss. Cytokines. Preprosthetic oral surgical procedures.

\section{INTRODUCTION}

Healing after tooth extraction and the subsequent dimensional changes related to alveolar bone resorption are well documented ${ }^{2,24,25}$. To minimize alveolar bone resorption after tooth extraction and to obtain better outcomes with dental implants, various techniques for socket preservation have been developed. Autogenous bone is the gold standard for bone grafts ${ }^{16}$. In practice, however, alloplastic materials are used more often ${ }^{24}$. Moreover, numerous studies have shown that there is less bone resorption when socket preservation is performed after extraction than when there is additional treatment, and a beneficial effect is obtained irrespective of the type of graft material used $^{24,28,31}$. On the other hand, there have been no reports suggesting the mechanism by which socket preservation reduces bone resorption. Furthermore, previous studies are mainly focused on the healing process in the alveolar socket and/ or alveolar bone ${ }^{24,28,31}$. Therefore, it is necessary to study healing process in gingiva adjacent to alveolar bone, especially the crestal area showing major post-extraction resorption.

Inflammation and the innate immune response are involved in the regulatory mechanism responsible for initiating the healing of fractured bones ${ }^{26}$. Inflammation is also closely related to the bone resorption seen under pathological conditions such as periodontitis, osteomyelitis and rheumatoid 
arthritis $^{21}$. Immunoglobulins produced by $B$ cells are present at sites of acute inflammation ${ }^{23}$. In addition, the inflammatory cytokine interleukin (IL) $-1 \beta$ and chemokines CXCL2 and CXCL5 are immediately up-regulated after tooth extraction, whereas CXCL12 levels rise gradually22. Finally, tumor necrosis factor-alpha (TNF-a) plays a key role in lipopolysaccharide (LPS)-induced inhibition of osteogenesis in a murine tooth extraction model $^{29}$. Taken together, these findings suggest that inflammation and immune response are related to the alveolar bone resorption seen after tooth extraction.

Both osteoblastic and osteoclastic activities are observed during bone healing ${ }^{5}$. Osteoclastogenesis is activated by receptor activator of nuclear factor kappa-B ligand (RANKL) and macrophage colonystimulating factor (M-CSF), as well as by various immune cell products ${ }^{19}$. It therefore seems plausible that an immune response in extraction socket could increase osteoclastic activity, leading to bone resorption. We hypothesized that alloplastic bone graft material suppresses osteoclastogenesis by suppressing immune responses. To test that idea, we investigated the immune response that occurs during wound healing after dental extraction, focusing on the bone resorption process, which might be altered by socket preservation.

\section{MATERIAL AND METHODS}

\section{Animal experimental procedures}

Nine miniature pigs (Sus scrofa; PWG Genetics Korea, Ltd., Pyeongtaek, Republic of Korea) were maintained under specific-pathogen free conditions. All animal-related procedures were reviewed and approved under the Animal Care Regulations (ACR) of Chonnam National University (No. CNU IACUC-
YB-2011-3). Nine pigs were divided into three groups ( $n=3$ in each group), depending on the time point of their sacrifice, as depicted in Figure 1. In three animals, the left premolars were used as controls, and the right premolars were extracted without socket preservation. These animals were sacrificed $3 \mathrm{~h}$ after the extraction (right: $3 \mathrm{~h}$ after the extraction; left: no extraction/control, $\mathrm{NE}$ ). In the remaining six animals, maxillary and mandibular premolars (PM1, PM2, and PM3) were extracted bilaterally, and the left extraction sockets were filled with graft material (right: extraction only, EO; left: extraction and socket preservation, SP). Three of these animals were sacrificed 1 week after the procedure, and the final three, 2 weeks after the procedure ( 1 week after the procedure, $1 \mathrm{~W}$; 2 weeks after the procedure, $2 \mathrm{~W}$ ). All extraction sockets were closed primarily. Biphasic calcium phosphate (BCP; Bone Plus ${ }^{\mathrm{TM}}$ BCP Eagle eye, MegaGen Implant Co., Ltd., Seoul, Republic of Korea) composed of $60 \%$ hydroxyapatite (HA) and $40 \%$ beta-tricalcium phosphate ( $\beta$-TCP) was used for socket preservation. After surgical procedures, the animals were monitored carefully, and no sign of postoperative infection was noted around the extraction site. The animals were euthanized humanely just before the collection of specimens. After the mini pigs were sacrificed, the alveolar process of the maxilla and mandibular body were harvested immediately. The specimens were stored in liquid nitrogen until analyzed. About $0.3 \mathrm{~g}$ of the gingiva of crestal area was carved out of the frozen specimens for analysis.

\section{LC-MS/MS peptide analysis}

For peptide analysis, gingival tissue was homogenized in buffer containing $1 \%$ Triton $\mathrm{X}-100$, 20 mM Tris- $\mathrm{HCl}(\mathrm{pH} 7.5), 150 \mathrm{mM} \mathrm{NaCl}, 1 \mathrm{mM}$ EDTA,
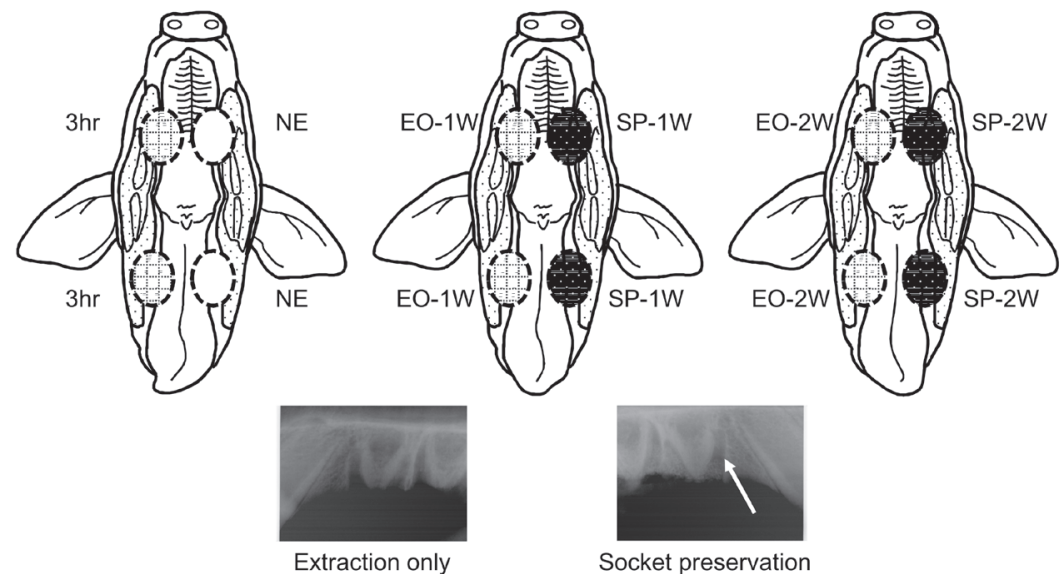

Figure 1- Overview of the animal experiment presented with a schematic drawing of swine oral cavity. Circles of dotted outline represent the following; 3hr: 3 hours after the extraction, right premolar extraction sockets; NE: no extraction/ control, left premolars; EO-1W: extraction only, 1 week post-extraction; SP-1W: extraction and socket preservation, 1 week after the procedures; EO-2W: extraction only, 2 weeks post-extraction; SP-2W: extraction and socket preservation, 2 weeks after the procedures. Arrow indicates socket filled with the graft material of biphasic calcium phosphate 
1 mM EGTA, 2.5 mM sodium pyrophosphate, $1 \mathrm{mM}$ $\beta$-glycerolphosphate, $1 \mathrm{mM}$ sodium orthovanadate, $25 \mathrm{mM}$ sodium fluoride, $1 \mu \mathrm{g} / \mathrm{ml}$ leupeptin and $1 \mathrm{mM}$ PMSF. Proteins extracted from gingiva after tooth extraction were analyzed using LCMS/MS as described previously ${ }^{32}$. To search via ProteinLynx GlobalServer search version 2.3.3 (Waters Corporation, Milford, MA, USA), the parent ion tolerance was set at $100 \mathrm{ppm}$, and the fragment ion tolerance was set at 0.2 Da. Carbamidomethylation (+57 Da) of cysteine and methionine oxidation (+16 Da) were chosen as the fixed and variable modifications, respectively.
Analysis of quantitative changes in protein abundance, based on measurements of peptide ion peak intensities observed in the low collision energy mode (MS) in a triplicate set, was carried out using the Expression ${ }^{\mathrm{TM}}$ software (version 2). To normalize comparative proteomic data, the "auto normalization" function of ProteinLynx GlobalServer was used. Protein identification was allowed only if the confidence was greater than $95 \%$ on the basis of the IDENTITYE algorithm.

Quantitative real-time PCR

Total RNA was isolated from samples using

\begin{tabular}{|c|c|c|c|}
\hline Gene name & Direction & Sequence & $\begin{array}{c}\text { Amplicon } \\
\text { size }\end{array}$ \\
\hline \multirow[t]{2}{*}{ CCR9 } & Forward & 5'-CCGCCGGGATCTTGTG-3' & $85 \mathrm{bp}$ \\
\hline & Reverse & 5'- GCTGCCCTCTCTCCTTGTGA-3' & \\
\hline \multirow[t]{2}{*}{ CCR10 } & Forward & 5'-GCCCGCAGAGCAGGTTT-3' & $111 \mathrm{bp}$ \\
\hline & Reverse & 5'-CGACTGAAGGCCTGGACATC-3' & \\
\hline \multirow[t]{2}{*}{ CCL3 } & Forward & 5'-CAGGTCTTCTCTGCACCACTTG-3' & $105 \mathrm{bp}$ \\
\hline & Reverse & 5'-GGTCTCAAAATAGTCGGCTACGA-3' & \\
\hline \multirow[t]{2}{*}{ CCL5 } & Forward & 5'-GGAATATTTCTACACCAGCAGCAAGT-3' & $91 \mathrm{bp}$ \\
\hline & Reverse & 5'-CTTCTCTGGGTTGGCACACA-3' & \\
\hline \multirow[t]{2}{*}{ CXCL2 } & Forward & 5'-TCAGGATAGCACGCTGTACCA-3' & $99 \mathrm{bp}$ \\
\hline & Reverse & 5'-САТАСААСССССССТАСССТАА-3' & \\
\hline \multirow[t]{2}{*}{ IFNy } & Forward & 5'-AGCGCAAAGCCATCAGTGA-3' & 82 bp \\
\hline & Reverse & 5'-TGACTTCTCTTCCGCTTTCTTAGG-3' & \\
\hline \multirow[t]{2}{*}{ IL-7 } & Forward & 5'-GTTCTGTTGCCAGTAGCATCATCT-3' & $113 \mathrm{bp}$ \\
\hline & Reverse & 5'-TCAAAGTCTATCATCCTGTCCAAGTC-3' & \\
\hline \multirow[t]{2}{*}{$\mathrm{TNF} \alpha$} & Forward & 5'-TCСССТGTCСАTСССТTТАTT-3' & $80 \mathrm{bp}$ \\
\hline & Reverse & 5'-CCAGCСССТСАTTCTСTTTCT-3' & \\
\hline \multirow[t]{2}{*}{ RANKL } & Forward & 5'-ACAACACATCAGAGCAGAAAAAGC-3' & $90 \mathrm{bp}$ \\
\hline & Reverse & 5'-TGGGCAAAGGGCTGAGTCT-3' & \\
\hline \multirow[t]{2}{*}{ OPG } & Forward & 5'-GGAGAGGATAAAACGACGACACA-3' & $84 \mathrm{bp}$ \\
\hline & Reverse & 5'-TCTTGGTCTTTGTTTTGATGTTTCC-3' & \\
\hline \multirow[t]{2}{*}{ Runx2 } & Forward & 5'-CAGCCACCGAGACCAACAG-3' & $92 \mathrm{bp}$ \\
\hline & Reverse & 5'-ATAGTCCСTCCTTTTTTTTTCAGATAGA-3' & \\
\hline \multirow[t]{2}{*}{ DKK1 } & Forward & 5'-GCAGAAAGCGCCGAAAAC-3' & $106 \mathrm{bp}$ \\
\hline & Reverse & 5'-CCTCGGTGGAAATGATTGTGA-3' & \\
\hline \multirow[t]{2}{*}{ IL-1 $\alpha$} & Forward & 5'-TGCCTGAGACACCCAAAACC-3' & $93 \mathrm{bp}$ \\
\hline & Reverse & 5'-GGGCGGCTGATTTGAAGTAGT-3' & \\
\hline \multirow[t]{2}{*}{$\mathrm{IL}-1 \beta$} & Forward & 5'-GCACCTCTCAAGCAGAACAAAA-3' & $114 \mathrm{bp}$ \\
\hline & Reverse & 5'-CCTCTGGGTATGGCTTTCCTT-3' & \\
\hline \multirow[t]{2}{*}{ IL-6 } & Forward & 5'-ССССТААССССАССАСАААТ-3' & $98 \mathrm{bp}$ \\
\hline & Reverse & 5'-AAGGCTGCGCAGGATGAG-3' & \\
\hline \multirow[t]{2}{*}{ IL-8 } & Forward & 5'-GCCAACACAACTTCAATCAAATCTA-3' & $88 \mathrm{bp}$ \\
\hline & Reverse & 5'-TGGGCATCCTGTGATTTCTCT-3' & \\
\hline
\end{tabular}

Figure 2- Primers used for the quantitative real-time PCR 
QIAzol ${ }^{\circledR}$ RNA Lysis reagent (QIAGEN, Hilden, Germany), after which cDNAs were synthesized using a PrimeScript ${ }^{T M}$ RT reagent Kit for RT-PCR (Takara Bio Inc., Otsu, Japan) according to the manufacturer's instructions. Quantitative PCR was performed using an ABI 7300 Prism SDS realtime PCR detection system (Applied Biosystems, Foster City, CA, USA) with a SYBR ${ }^{\circledR}$ Premix Ex Tag kit (Takara Bio Inc., Otsu, Japan) and a standard temperature protocol. The results obtained using CT (cycle threshold) were expressed as relative quantities and were calculated using the $2^{-\triangle \Delta C T}$ method (expressed as relative fold ratio). Hypoxanthine phosphoribosyltransferase 1 (HPRT1) was used as a control gene for normalization, and three separate experiments were performed. Detailed primer information is shown in Figure 2.

\section{Statistical analysis}

The results of real-time PCR were expressed as mean values with standard deviations ( $\pm S D$ ). For statistical significance, changes of mRNA expression level in control and experimental groups were analyzed using ANOVA. Differences between the control and $3 \mathrm{~h}$ and those between the EO and SP groups at same time point were analyzed using paired $t$-tests. Values of $p<0.05$ were considered significant. All statistical tests were performed using SigmaPlot software version 10.0 (Systat Software Inc., San Jose, CA, USA).

\section{RESULTS}

\section{Peptide analysis of immunoglobulins expressed in gingiva}

The relative expression levels of immunoglobulin peptides are summarized in Figure 3. In the EO group, levels of immunoglobulin $M$ (IgM) and immunoglobulin light chain (IGL) were respectively 1.7-fold and 1.3-fold higher 1 week after tooth extraction than they were $3 \mathrm{~h}$ after tooth extraction. By 2 weeks, however, the expression levels had fallen to the same levels seen after $3 \mathrm{~h}$. By contrast, immunoglobulin G (IgG) expression increased throughout the experimental period. In the SP group, IgM and IGL declined throughout the experimental period and were dramatically reduced after 2 weeks. Levels of IgG, on the other hand, were lower after 1 week than after $3 \mathrm{~h}$, but the level was somewhat higher after 2 weeks. Overall, the expression levels of all three immunoglobulins (IgG, IgM and IGL) were higher in the EO group than in the SP group. In addition, the pattern of immunoglobulin expression differed between the EO and SP groups. In particular, whereas IgM and IGL levels peaked after 1 week in the EO group, they declined over the entire course of the experiment in the SP group.

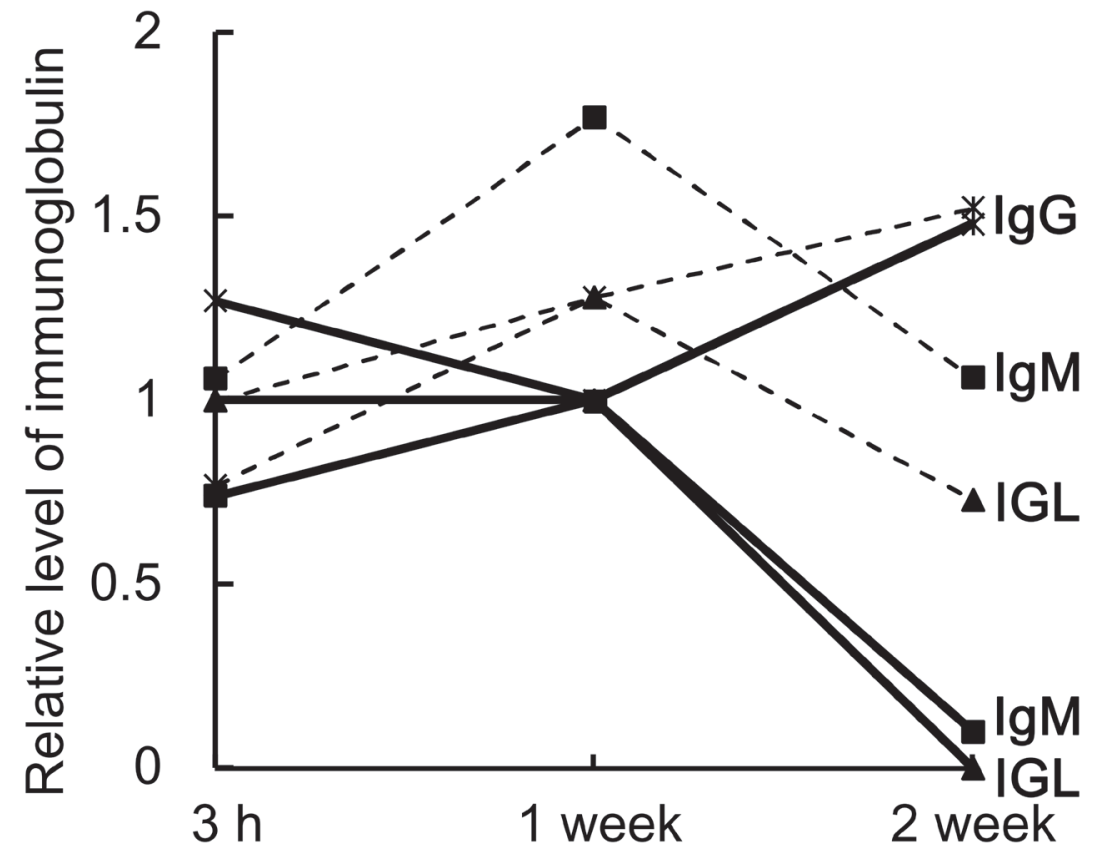

Figure 3- Relative levels (fold) of immunoglobulin M (IgM), immunoglobulin G (IgG) and immunoglobulin light chain (IGL) determined through peptide analysis in extraction only (EO) groups (dotted lines) and extraction with socket preservation (SP) groups (solid lines). Whereas IgM (lines with solid squares) and IGL (lines with solid triangles) appeared to peak 1 week after tooth extraction, IgG (lines with asterisks) levels were higher after 2 weeks in both groups (EO and SP group). Immunoglobulins were generally higher in EO groups than the SP groups 
Assessing the immune response: cytokines and chemokines in the EO and SP groups

To evaluate the effect of socket preservation on the immune response following tooth extraction, we examined the mRNA expression of several cytokines and chemokines (Figure 4). Three hours after extraction, levels of most of the inflammatory cytokines and chemokines tested (CCR10, CCR9, CCL3, CXCL2, IFNY, and TNF- $\alpha$ ) increased slightly, as compared to control (NE), while levels of CCL5 and IL-7 were lower than in the NE group.
Differences between the groups were significant in CCR9, CCL5, CXCL2, IL7, and TNF- $\alpha$. The cytokine and chemokine responses seen at $3 \mathrm{~h}$ are known as the early immune response, which is triggered by bleeding following tooth extraction ${ }^{32}$. At 1 week postextraction, levels of the inflammatory chemokines CCL3, CCL5, and CXCL2 and the chemokine receptors CCR9 and CCR10 had declined in the SP group, as compared to the EO group (however, CCR9 showed no statistical significance.). Similarly, expression of the pro-inflammatory cytokines TNF-a
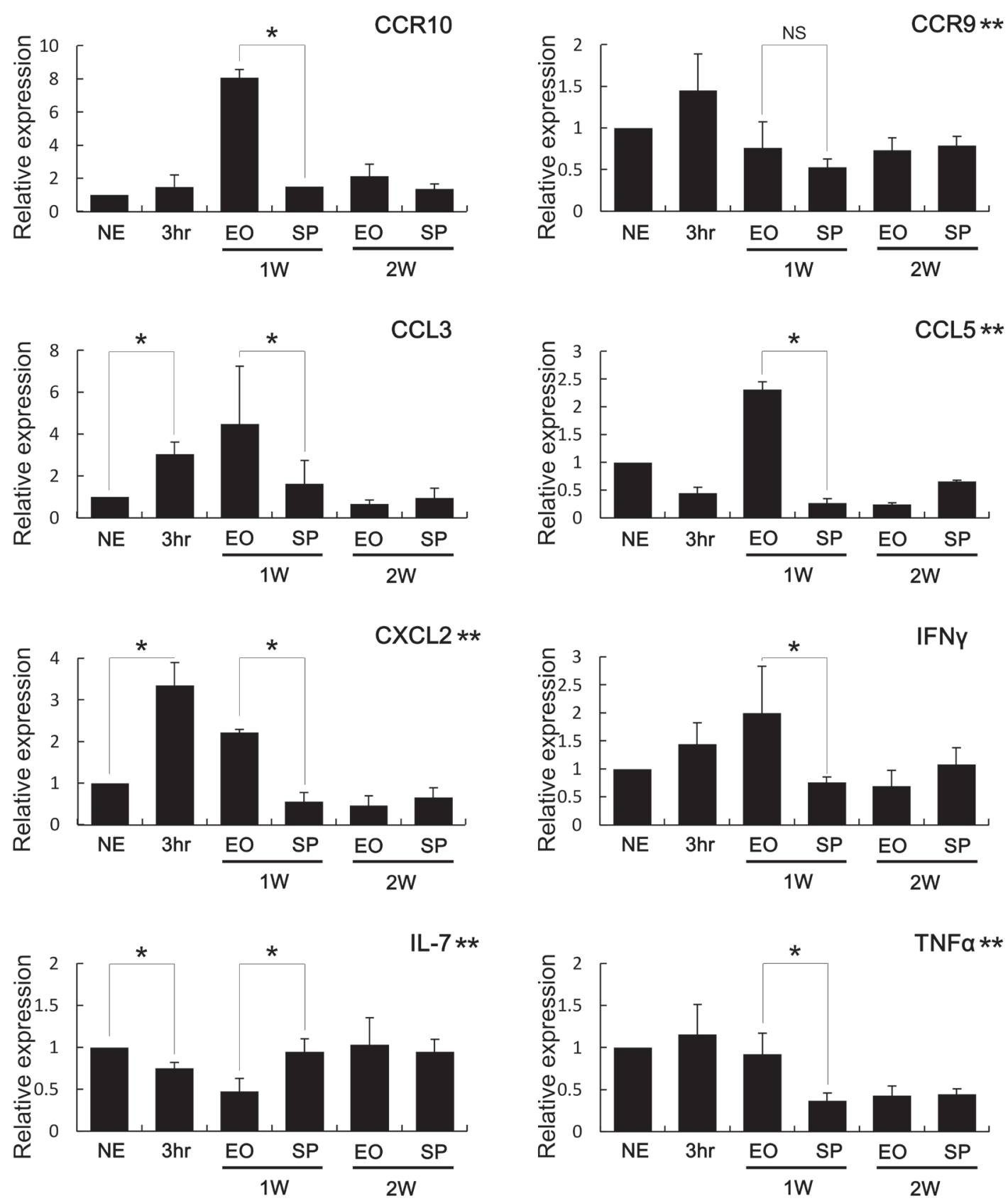

Figure 4- Relative mRNA expression of the indicated chemokines and inflammatory cytokines. Levels of CCR10, CCL3, CCL5, CXCL2, IFN-y and TNF- $\alpha$ mRNA were significantly higher in the EO group than in the SP group 1 week after tooth extraction (1W). Levels of CCR9 and IL-7 mRNA did not significantly differ between groups. NE: no extraction; $3 \mathrm{hr}: 3 \mathrm{~h}$ after the extraction; EO: extraction only; SP: extraction and socket preservation; NS: non-significant; *: $p<0.05$ in paired t-test; **: $p<0.05$ in ANOVA 
and interferon-gamma (IFN-y) were significantly lower in the SP group than in the EO group, whereas expression of the anti-inflammatory cytokine IL-7 was significantly higher in the SP group than in the EO group. Within 2 weeks after tooth extraction, however, there were no differences in the levels of cytokine and chemokine expression between the EO and SP groups.
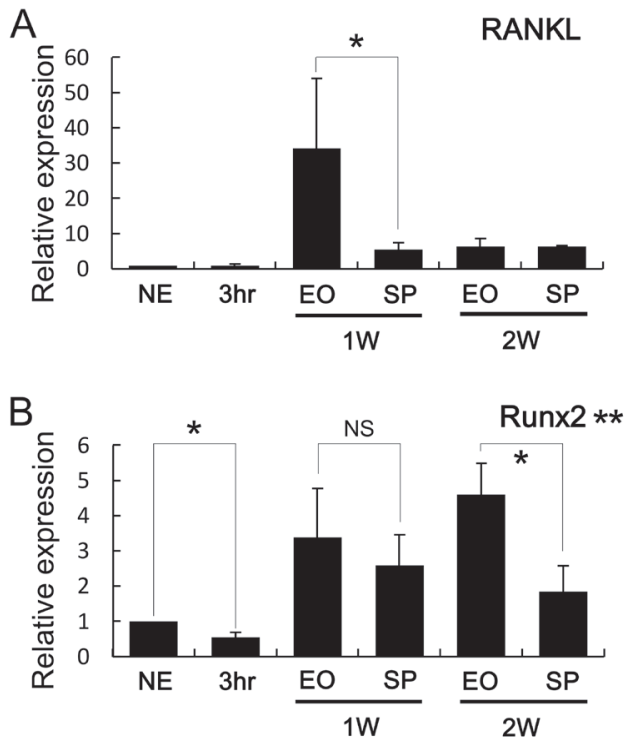

Cytokines related to canonical osteoclastogenesis

To assess osteoblastic activity, we examined the mRNA levels of RANKL, osteoprotegerin (OPG), runt-related transcription factor (2Runx2) and Dickkopf-related protein 1 (DKK1). OPG and Runx2 presented significant differences. Overall, the expression levels of all of the osteoblast-
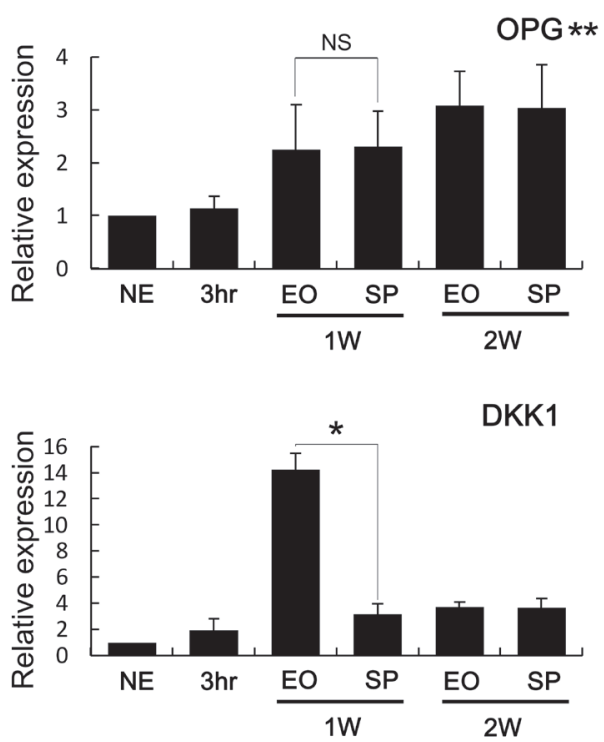

Figure 5- (A) mRNA expression related to osteoclastic activation. Levels of receptor activator of nuclear factor kappa-B ligand (RANKL) expression were significantly higher in the EO group 1 week after tooth extraction (1W). Osteoprotegerin (OPG) levels did not differ between groups; (B) mRNA expression related to osteoblastic activation. Levels of DKK1 expression were significantly higher in the EO group 1 week after tooth extraction. Levels of Runx2 mRNA were significantly higher in the EO than in the SP group 2 weeks post-extraction (2W). NE: no extraction; EO: extraction only; SP: extraction and socket preservation; NS: non-significant; *: $p<0.05$ in paired t-test; ${ }^{* *}$ : $p<0.05$ in ANOVA
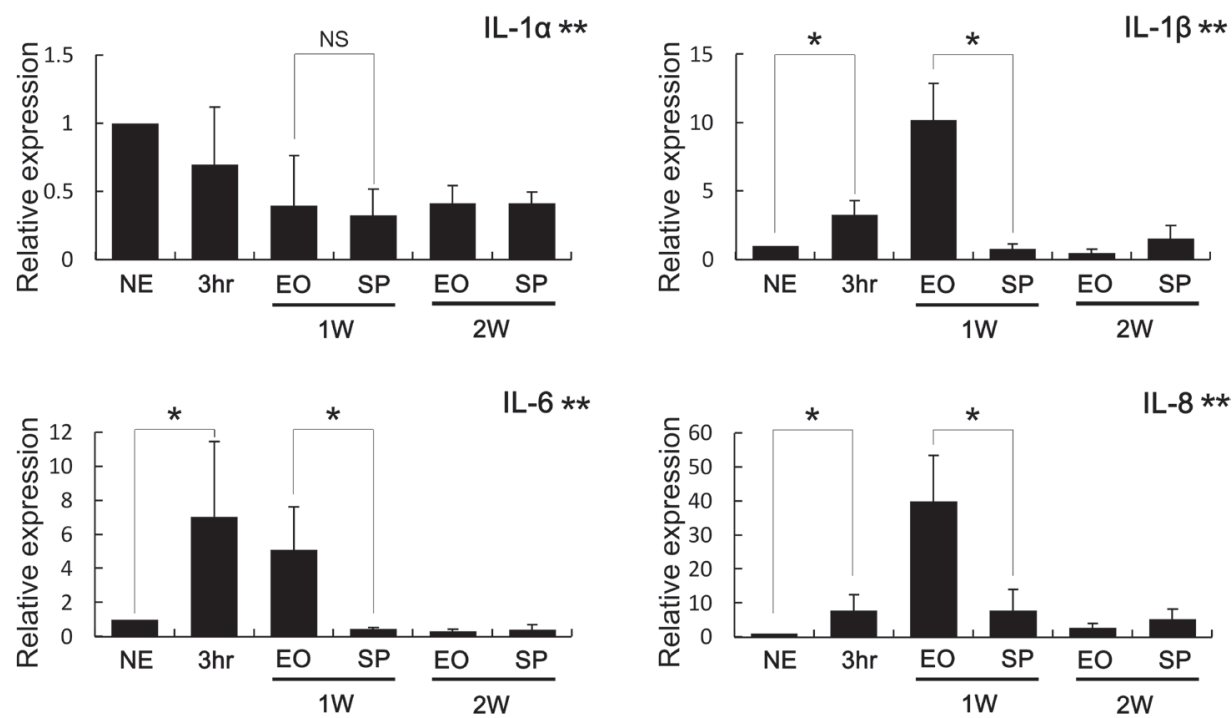

Figure 6- Expression of interleukins related to non-canonical osteoclastogenesis. Expression levels of IL-1 $\beta$, IL-6 and IL-8 were significantly higher in the EO group than in the SP group 1 week after tooth extraction (1W). While IL-1 $\alpha$ expression level decreased after the extraction, the levels of EO and SP were similar at 1 week and 2 weeks (1W, 2W). NE: no extraction; EO: extraction only; SP: extraction and socket preservation; NS: non-significant; *: $p<0.05$ in paired t-test; **: $p<0.05$ in ANOVA 
related genes were higher in the EO group than the SP group 1 week post-extraction (Figure 5). In particular, RANKL expression was increased to a dramatically greater degree in the EO group (34.1fold) than in the SP group (5.6-fold) at 1 week. By 2 weeks, however, the expression was similarly increased in the two groups (6.4-fold). The level of OPG expression gradually increased over time, and did not differ between the EO (2.3-fold at 1 week; 3.1-fold at 2 weeks) and SP (2.3-fold at 1 week; 3-fold at 2 weeks) groups. The level of Runx2 expression was higher in the EO than the SP group 1 week post-extraction (3.4-fold in EO group vs. 2.6-fold in SP group), and the difference reached significance by 2 weeks. Finally, the level of DKK1 expression was significantly higher in the EO group (14.2-fold) than in the SP group (3.2-fold) after 1 week, but the expression levels in the two groups were the same as the expression levels at 2 weeks (3.7-fold).

\section{Interleukins related to non-canonical osteoclastogenesis}

We also investigated the post-extraction expression of interleukins known to activate osteoclasts, and changes in IL- $1 \alpha$, IL-1 $\beta$, IL6, and IL8 were significant (Figure 6). One week post-extraction, gingival expression of IL-1 $\beta$ was dramatically higher in the EO group than in the SP group. In addition, the levels of IL- 6 and IL- 8 expression were also significantly higher in the EO group. However, IL-6 expression was also dramatically increased $3 \mathrm{~h}$ after tooth extraction, suggesting it may be involved in the acute immune response induced by bleeding following the extraction.

\section{DISCUSSION}

Osteoclasts have been observed in the crestal region of alveolar bone during the healing process after tooth extraction ${ }^{2}$. This suggests osteoclasts are likely responsible for the bone resorption seen after extraction, and the factors related to bone resorption present in the adjacent gingiva should be evaluated.

Bleeding after extraction may induce nonspecific gene expression related to the early immune response ${ }^{9}$. We compared the ongoing expression $3 \mathrm{~h}$ after extraction in the NE, EO and SP groups to avoid misinterpreting the results due to the influence of bleeding. Both B cells and $\mathrm{T}$ cells are abundant within the extraction socket ${ }^{30}$, and the presence of immunoglobulin would reflect lymphocyte infiltration into the adjacent gingiva, activating an inflammatory response around the extraction socket. Levels of all the identified immunoglobulins, IgM, IgG and IGL, were higher in the EO group than in the SP group (Figure 3). Higher levels of IGL suggest greater $B$ cell activation and inflammation in the EO group ${ }^{15}$. The importance of inflammation to alveolar bone resorption is illustrated by the finding that oral Porphyromonas gingivalis infection induces less alveolar bone resorption in immunodeficient mice than in immunocompetent mice $^{3}$. Similarly, the stronger immune response in the EO group may lead to greater bone resorption.

A variety of cytokines and chemokines contribute to the post-extraction immune response ${ }^{13}$, and several are involved in osteoclastogenesis. For example, CCL3 and CCL5 are related to osteoclast activation or formation ${ }^{18,27}$, while CXCL2 plays a key role in neutrophil chemotaxis. Moreover, $\mathrm{CXCL} 2$ is reportedly induced by RANKL, which in turn enhances osteoclastogenesis ${ }^{11}$. IFN- $\gamma$ is a pro-inflammatory cytokine that activates plasma cells, B cells and macrophages, and is also reported to stimulate bone resorption through stimulation of RANKL and TNF- $\alpha$ production in $\mathrm{T}$ cells ${ }^{10}$. Conversely, IL-7, which is required for normal adult progenitor B cell development, reportedly inhibits osteoclastogenesis in a murine model ${ }^{1}$. As shown in Figure 3, the stronger expression of these cytokines and chemokines in the EO group compared with the SP group is consistent with the higher immunoglobulin levels revealed by the peptide analysis. This suggests that B cells are activated to a greater degree in the EO group, and that B cells are a likely source of RANKL in compromised gingiva ${ }^{17}$.

Runx2 is a well-known mediator of osteoblastic differentiation, while RANKL and OPG respectively induce and inhibit osteoclastogenesis ${ }^{4}$. Levels of Runx2, RANKL and OPG expression were all increased 1 and 2 weeks after tooth extraction, suggesting activation of osteoblasts. Interestingly, Runx2 expression was significantly higher in the EO group 2 weeks post-extraction. This might be related to repressed bone healing in socket, as in a previous study which reported that biomaterials grafted to fresh extraction sockets may interfere with the normal healing processes of the alveolar bone and present poor bone quality ${ }^{7}$. While the level of OPG and Runx2 expression did not differ significantly between the EO and SP groups, RANKL expression was significantly higher in the EO group than in the SP group 1 week post-extraction. RANKL is secreted by osteoblasts as well as immune cells ${ }^{12,19}$, and its upregulation (Figure 5 ) may imply infiltration of immune cells into the gingiva adjacent to the extraction socket. Moreover, it appears that higher gingival expression of RANKL may lead to enhanced osteoclastogenesis and subsequent marginal bone resorption. It has been reported that TNF- $\alpha$-induced DKK1 expression impairs local bone formation in a murine inflammatory arthritis 
model and in human rheumatoid arthritis ${ }^{8}$. It also appears TNF-a may play a major role in LPS-induced inhibition of osteogenesis in areas of inflammation ${ }^{29}$, and upregulation of DKK1 is thought to be related to inflammation-induced upregulation of TNF-a (Figure 4 and 5B).

IL-1, which is produced by polymorphonuclear neutrophils, monocytes and macrophages in the periodontium, stimulates bone resorption via effects on osteoclasts ${ }^{19}$ and plays a significant role in the pathogenesis of periodontal tissue destruction ${ }^{14}$. IL-6, which is initially upregulated by stimulation of IL-1, is reportedly capable of inducing osteoclast formation from circulating cells ${ }^{20}$. Consistent with that finding, the alveolar bone resorption in an oral infection model was diminished in the absence of IL$6^{3}$. In addition, IL-8, which is stimulated by RANKL, enhances RANKL-induced osteoclastogenesis ${ }^{18}$. Interestingly, IL-1, IL- 6 and IL- 8 together coordinate osteoclastogenesis in a RANKL-independent manner ${ }^{19}$. Collectively, these findings indicate that the upregulation of IL- 1 , IL- 6 and IL- 8 may account for the greater osteoclastogenesis seen in the EO group compared with the SP group 1 week after tooth extraction.

In this study, we observed that levels of cytokines associated with inflammation and osteoclastogenesis were lower in the SP group than in the EO group. This suggests that grafting alloplastic material into the extraction socket after tooth extraction may suppress the inflammatory cytokines and osteoclastogenic mediators in the gingiva adjacent to the socket. It might be related to fibrin, which is a major component of blood clot. Since graft material fills the alveolar socket, the amount of blood clot is smaller in the SP group. It was recently suggested that fibrin may be an exogenous activator of the bone remodeling unit, favoring bone resorption ${ }^{6}$. Since, however, the forementioned study described a systemic effect of fibrin accumulation, it is considered that further study about the local effect of fibrin on bone healing should be followed.

\section{ACKNOWLEDGEMENTS}

This work was supported by the Basic Science Research Program through the National Research Foundation of Korea (NRF) funded by the Ministry of Science, ICT and future Planning (MSIP) (2014R1A2A2A01005448), and by the National Research Foundation of Korea (NRF) grant funded by the Korean government (2011-0030121).

\section{REFERENCES}

1- Aguila HL, Mun SH, Kalinowski J, Adams DJ, Lorenzo JA, Lee SK. Osteoblast-specific overexpression of human interleukin-7 rescues the bone mass phenotype of interleukin-7-deficient female mice. J Bone Miner Res. 2012;27(5):1030-42.

2- Araújo MG, Lindhe J. Dimensional ridge alterations following tooth extraction. An experimental study in the dog. J Clin Periodontol. 2005;32(2):212-8.

3- Baker PJ, Dixon M, Evans RT, Dufour L, Johnson E, Roopenian DC. $\mathrm{Cd} 4(+)$ t cells and the proinflammatory cytokines gamma interferon and interleukin- 6 contribute to alveolar bone loss in mice. Infect Immun. 1999;67(6):2804-9.

4- Boyce BF, Xing L. Functions of RANKL/RANK/OPG in bone modeling and remodeling. Arch Biochem Biophys. 2008;473(2):139-46.

5- Cardaropoli G, Araújo M, Lindhe J. Dynamics of bone tissue formation in tooth extraction sites. An experimental study in dogs. J Clin Periodontol. 2003;30(9):809-18.

6- Cole HA, Ohba T, Nyman JS, Hirotaka H, Cates JM, Flick MJ, et al. Fibrin accumulation secondary to loss of plasmin-mediated fibrinolysis drives inflammatory osteoporosis in mice. Arthritis Rheumatol. 2014;66(8):2222-33.

7- De Coster P, Browaeys H, De Bruyn H. Healing of extraction sockets filled with BoneCeramic ${ }^{\circledR}$ prior to implant placement: preliminary histological findings. Clin Implant Dent Relat Res. 2011;13(1):34-45.

8- Diarra D, Stolina M, Polzer K, Zwerina J, Ominsky MS, Dwyer $D$, et al. Dickkopf-1 is a master regulator of joint remodeling. Nat Med. 2007;13(2):156-63.

9- Esmon CT. The interactions between inflammation and coagulation. Br J Haematol. 2005;131(4):417-30.

10- Gao Y, Grassi F, Ryan MR, Terauchi M, Page K, Yang X, et al. Ifn-gamma stimulates osteoclast formation and bone loss in vivo via antigen-driven $\mathrm{T}$ cell activation. J Clin Invest. 2007;117(1):122-32.

11- Ha J, Choi HS, Lee Y, Kwon HJ, Song YW, Kim HH. CXC chemokine ligand 2 induced by receptor activator of NFkappa b ligand enhances osteoclastogenesis. J Immunol. 2010;184(9):4717-24.

12- Horowitz MC, Fretz JA, Lorenzo JA. How b cells influence bone biology in health and disease. Bone. 2010;47(3):472-9.

13- Horuk R. Chemokine receptors. Cytokine Growth Factor Rev. 2001;12(4):313-35.

14- Hou LT, Liu CM, Liu BY, Lin SJ, Liao CS, Rossomando EF. Interleukin-1beta, clinical parameters and matched cellularhistopathologic changes of biopsied gingival tissue from periodontitis patients. J Periodontal Res. 2003;38(3):247-54.

15- Hutchison CA, Landgren $O$. Polyclonal immunoglobulin free light chains as a potential biomarker of immune stimulation and inflammation. Clin Chem. 2011;57(10):1387-9.

16- Kao ST, Scott DD. A review of bone substitutes. Oral Maxillofac Surg Clin North Am. 2007;19(4):513-21.

17- Kawai T, Matsuyama T, Hosokawa Y, Makihira S, Seki M, Karimbux NY, et al. B and t lymphocytes are the primary sources of RANKL in the bone resorptive lesion of periodontal disease. Am J Pathol. 2006;169(3):987-98.

18- Kim MS, Day CJ, Morrison NA. MCP-1 is induced by receptor activator of nuclear factor-\{kappa\}B ligand, promotes human osteoclast fusion, and rescues granulocyte macrophage colonystimulating factor suppression of osteoclast formation. J Biol Chem. 2005;280(16):16163-9.

19- Knowles HJ, Athanasou NA. Canonical and non-canonical pathways of osteoclast formation. Histol Histopathol. $2009 ; 24(3): 337-46$.

20- Kudo O, Sabokbar A, Pocock A, Itonaga I, Fujikawa Y, Athanasou NA. Interleukin-6 and interleukin-11 support human osteoclast formation by a RANKL-independent mechanism. Bone. 2003;32(1):1-7. 
21- Lerner UH. Inflammation-induced bone remodeling in periodontal disease and the influence of post-menopausal osteoporosis. J Dent Res. 2006;85(7):596-607.

22- Lin Z, Rios HF, Volk SL, Sugai JV, Jin Q, Giannobile WV. Gene expression dynamics during bone healing and osseointegration. J Periodontol. 2011;82(7):1007-17.

23- Male D. Mechanisms of innate immunity. In: Male D, Brostoff J, Roth D, Roitt I, ed. Immunology. London: Elsevier Health Sciences; 2012. p. 109-16.

24- Morjaria KR, Wilson R, Palmer RM. Bone healing after tooth extraction with or without an intervention: a systematic review of randomized controlled trials. Clin Implant Dent Relat Res. 2014;16(1):1-20.

25- Scala A, Lang NP, Schweikert MT, Oliveira JA, Rangel-Garcia I Jr, Botticelli D. Sequential healing of open extraction sockets. An experimental study in monkeys. Clin Oral Implants Res. $2014 ; 25(3): 288-95$.

26- Steen BM, Gerstenfeld LC, Einhorn TA. The role of the immune system in fracture healing. In: Lorenzo J, Choi Y, Horowitz M, Takayanagi $\mathrm{H}$, ed. Osteoimmunology. London: Academic Press; 2010. p. 343-67.
27- Terpos E, Politou M, Viniou N, Rahemtulla A. Significance of macrophage inflammatory protein-1 alpha (MIP-1alpha) in multiple myeloma. Leuk Lymphoma. 2005;46(12):1699-707.

28- Tomlin EM, Nelson SJ, Rossmann JA. Ridge preservation for implant therapy: a review of the literature. Open Dent J. 2014;8:66-76.

29- Tomomatsu N, Aoki K, Alles N, Soysa NS, Hussain A, Nakachi $\mathrm{H}$, et al. LPS-induced inhibition of osteogenesis is TNF-alpha dependent in a murine tooth extraction model. J Bone Miner Res. $2009 ; 24(10): 1770-81$.

30- Trombelli L, Farina R, Marzola A, Bozzi L, Liljenberg B, Lindhe J. Modeling and remodeling of human extraction sockets. J Clin Periodontol. 2008;35(7):630-9.

31- Wang RE, Lang NP. Ridge preservation after tooth extraction. Clin Oral Implants Res. 2012;23 Suppl 6(147-56.

32- Yang HY, Kwon J, Kook MS, Kang SS, Kim SE, Sohn S, et al. Proteomic analysis of gingival tissue and alveolar bone during alveolar bone healing. Mol Cell Proteomics. 2013;12(10):2674-88. 